\title{
Effect of Different Finishing and Polishing Techniques on Surface Roughness of Two Universal Nanohybrid Composite Resins
}

\author{
Ebaa Alagha $^{1 *}$, Waad Alotaibi ${ }^{2}$, Maha Magharbil ${ }^{2}$, Layla Hakami ${ }^{2}$, Maram Alrashedi $^{2}$ \\ ${ }^{1}$ Department of Operative Dentistry, Al-Farabi Private Colleges, Jeddah, Saudi Arabia; ${ }^{2}$ Dental Intern students, Al-Farabi Private \\ Colleges, Jeddah, Saudi Arabia
}

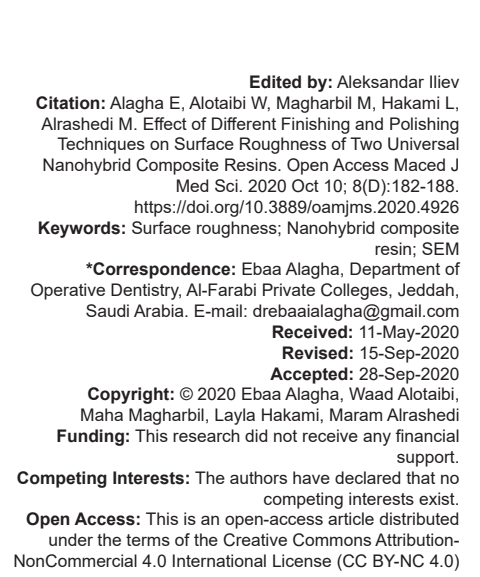

Introduction

Esthetics has become a prime requirement in the current world. Longevity of any restoration defines its clinical success [1]. Nowadays, composite resins considered as the most popular direct restorative material despite its disadvantages regarding polymerization shrinkage and post-operative sensitivity [2]. Composite resins are versatile tooth-colored restorative materials, and indeed the most widely used material for restoration of anterior teeth [3]. It was introduced by Bowen (1962) and no other restorative material has been so modified and improved as it [4]. Universal hybrid composite provides the best general blend of good material properties and clinical performance for routine anterior and posterior restorations [5]. Furthermore, with the use of nanotechnology in the composite resins formulations is one of the most promising contributions to dental materials [6]. They offer high translucency, high polish, and superior gloss as well as adequate mechanical properties suitable for high stress-bearing restorations [7]. Unfortunately, heterogeneous nature of composite resin restorations complicates the polishing of the restorations [8]. Proper finishing and polishing of dental restorative materials are critical clinical procedures and particularly important for the esthetics and longevity of restorations. Different methods could be used to finish and polish composite resin restorations [9], and it is well known that few, and possibly, none are as efficient as the polyester strip. However, the use of this strip is limited by the complexity of the tooth anatomy and by diverse restorative procedures. Other finishing and polishing methods such as discs are nondestructive, but their effect on anatomically contoured occlusal surfaces is limited because they cannot access the narrow fissures on the surface for geometric reasons [10]. The different use of finishing and polishing methods improves esthetics provided by these materials, due to the smoother surface obtained after polishing and higher wear resistance ( $<10 \mu \mathrm{m} / \mathrm{year})$, which led to their recommendation for placement in anterior and posterior teeth. In many clinical studies, several nanohybrid composite resins with these characteristics showed excellent clinical performance [7]. Hence, proper finishing and polishing of dental restoratives are critical clinical procedures that enhance the esthetics and longevity of restorations [9]. Restoration finish, surface roughness, and surface integrity, and the physicochemical properties of the material itself, can influence plaque retention, periodontal disease, and 
recurrent caries, thus affecting the clinical performance of materials [8].

\section{Materials and Methods}

A total number of 40 samples were prepared to form two main equal groups of specimens $(n=20)$, according to the composite resin materials. Two different universal nanohybrid resin composites were used in this study. First group (A1) is a universal nanohybrid composite resin (Mosaic) and the second group (A2) is a universal nanohybrid composite resin (Harmonize) (Figure 1). Each group was subdivided equally into four equal subgroups $(n=5)$, according to the used finishing and polishing systems. The variables of the study and their interactions are listed in Table 1. Mold was made to prepare the specimens with a central hole of $4 \mathrm{~mm}$ in diameter and $4 \mathrm{~mm}$ in thickness.

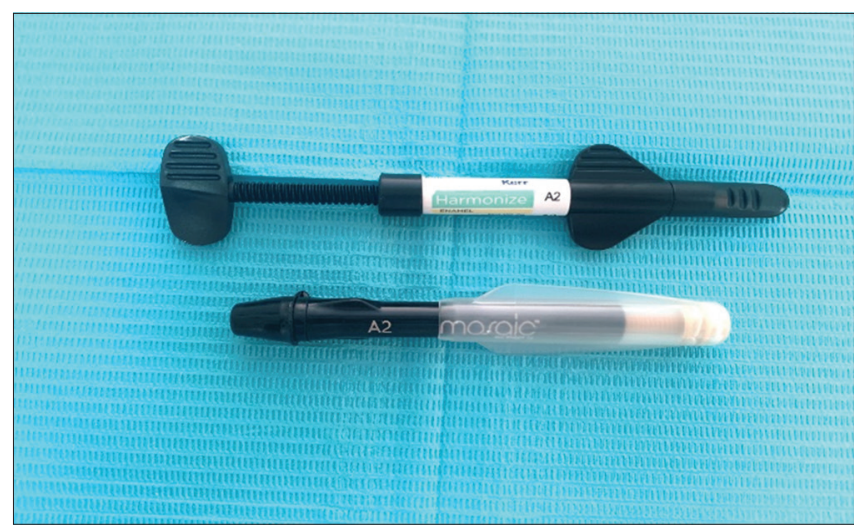

Figure 1: Harmonize and mosaic resin composite

The mold was placed on a glass slab then packed with composite using Teflon applicator to prevent adherence of the resin composites to it. The specimens were covered with a Mylar strip and another glass slab to compress the surface using terminal light finger pressure before and during polymerization to extrude excess material [11]. Light curing tip was placed touching the glass slab. The guide of the light-curing unit was placed perpendicular to the specimen surface and the curing was done for $20 \mathrm{~s}$ according to the manufacture instruction [12]; then, the cured specimen was removed from the mold and the specimens immediately and immersed in distilled water at $37^{\circ} \mathrm{C}$ for $24 \mathrm{~h}$ [13].

Table 1: Variables of the study

\begin{tabular}{llll}
\hline Variable & Symbol & Representing & Lot No \\
\hline Composite resins (A) & A1 & $\begin{array}{l}\text { Nanohybrid universal resin } \\
\text { composites(Mosaic) } \\
\text { Nanohybrid universal resin } \\
\text { composites (Harmonize) }\end{array}$ & BFYSB \\
& A2 & $\begin{array}{l}\text { Control/Mylar strip } \\
\text { Polishing Discs }\end{array}$ & DENCO \\
Finishing and & B1 & White polishing stones & Dentex \\
polishing system (B) & B2 & Diacomp plus & 2203 \\
& B3 & Gz \\
& B4 & 9073 \\
\hline
\end{tabular}

Surface roughness $(\mathrm{Ra})$ was measured using a light sectioning vision system. After measuring the final (Ra), the sample nearest to the mean (Ra) of each subgroup was selected as a representative sample and observed under a scanning electron microscope (Model JSM-550 Lv; Jeol Ltd. - Japan). The specimens were sputter-coated with gold, using a sputtering device to allow for a film thickness of gold of $150^{\circ} \mathrm{A}$. Then, the specimens were examined under the SEM at a magnification of $\times 500$. The data obtained were recorded, tabulated, and statistically analyzed.

\section{Results}

Data analysis was performed in several steps. One-way ANOVA followed by pair-wise Newman-Keuls post-hoc tests were performed to detect significance between subgroups. A student's t-test was performed to detect significance between groups. Statistical analysis was performed using Assistat 7.6 beta statistics software for Windows. $p \leq 0.05$ is statistically significant in all tests.

Table 2: Roughness results (mean \pm SD) for both resin composites materials as function of finishing and polishing techniques

\begin{tabular}{|c|c|c|c|c|c|}
\hline \multirow[t]{2}{*}{ Variable } & & \multicolumn{2}{|c|}{$\begin{array}{l}\text { Mosaic composite } \\
\text { resin }\end{array}$} & \multicolumn{2}{|c|}{$\begin{array}{l}\text { Harmonize } \\
\text { composite resin }\end{array}$} \\
\hline & & Mean & SD & Mean & SD \\
\hline \multirow{4}{*}{$\begin{array}{l}\text { Finishing and } \\
\text { polishing systems }\end{array}$} & Control & 0.2554 & 0.000756 & 0.2562 & 0.00133 \\
\hline & Polishing discs & 0.2557 & 0.000688 & 0.2564 & 0.000811 \\
\hline & White stone & 0.2561 & 0.001237 & 0.2568 & 0.000936 \\
\hline & Diacomp plus & 0.2556 & 0.00071 & 0.2567 & 0.001062 \\
\hline
\end{tabular}

The results showed that the lowest $(\mathrm{Ra})$ values were recorded by the specimens under Myler strip followed by polishing discs treated specimens followed by Diacomp Plus specimens, the highest $(\mathrm{Ra})$ values were recorded by white polishing stone specimens. Roughness ( $\mathrm{Ra}$ ) results (mean $\pm \mathrm{SD}$ ) for both resin composites materials as a function of finishing and polishing are summarized in Table 2 and Figures 2 and 3 and regardless to finishing or polishing, it was found that mosaic resin composites group recorded statistically significant $(p<0.05)$ lower roughness mean value than Harmonize resin composites group.

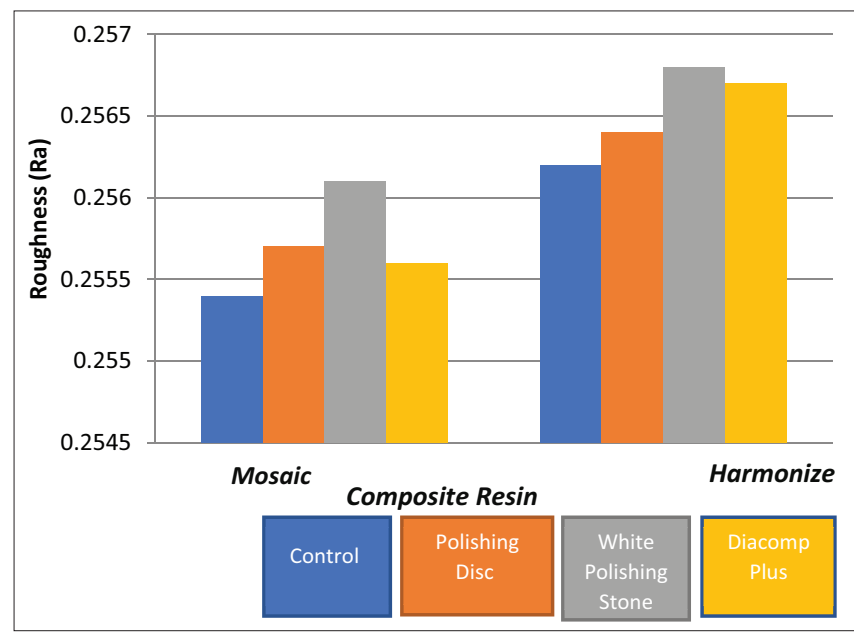

Figure 2: A column chart of the mean values of roughness for both resin composites materials as a function of finishing and polishing techniques 


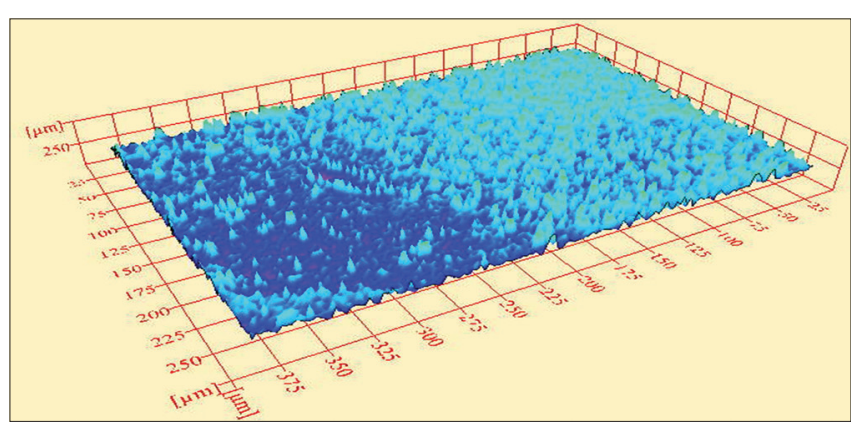

Figure 3: Surface roughness of Harmonize resin composite materials as a function of finishing and polishing systems (Polishing Discs)

Representative samples nearest to mean surface roughness ( $\mathrm{Ra}$ ) values after finishing with different finishing and polishing systems, as well as the control groups of all tested resin composites, were evaluated under SEM. In our study, the SEM evaluation largely supports the $(\mathrm{Ra})$ results obtained by the light sectioning vision system used in Figure 4.

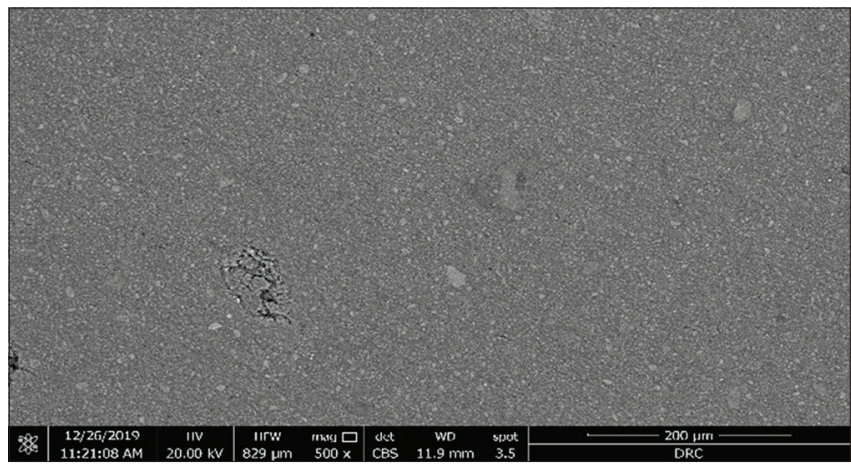

Figure 4: Polishing discs subgroup of Harmonize composite resin at $\times 500$ magnification as shown, the surface has no pitting or scratches, and it is almost smooth

\section{Discussion}

Esthetic restoration can be imperceptible only if its surface closely resembles enamel surface [14]. Proper finishing of restorations is desirable not only for esthetic considerations but also for oral health. The primary goal of finishing is to obtain a restoration that has good contour, occlusion, healthy embrasure forms, and a smooth surface, so bacterial adhesion to the surface of composite resins and other dental restorative materials which is an important parameter in the etiology of secondary caries formation is reduced [15]. A literature review has pointed out that the surface roughness $(\mathrm{Ra})$ of restorations should not be more than $0.2 \mu \mathrm{m}$ to avoid an increase in bacterial adhesion to the restorative materials [16]. The effectiveness of finishing/ polishing procedures on the composite surface is an important goal to be achieved in the restorative process [14]. Two factors affect the quality of polishing: The material used for restoration and the finishing and polishing procedures adopted [17]. Polishing is complicated by the heterogeneous nature of these dental materials, that is, hard filler particles embedded in a relatively soft matrix. Some other factors affecting the polishability of resin restorations are filler content, particle size, polishing medium, and polishing technique [18]. In addition, the effect of composition, degree of conversion, finishing, and polishing procedures can also affect the surface quality of composite resins. For this reason, the surface finish of composite resin is dependent on the microstructure and also on the finishing and polishing systems used to modify their surface [19]. More valid predictions of clinical performance can be made when the surface roughness measurements are combined with an SEM analysis that permits evaluation of the destructive potential of a finishing tool [20]. In this study, surface roughness measurements were used for relative comparisons, and the results of the measurements were largely confirmed by SEM analysis [6]. The use of nanotechnology induces the resin composites manufacturers to develop new type of resin composites, such as nanofilled and nanohybrid resin composites materials both for anterior and posterior tooth restorations. The resin composites with nanosize particles in its composition are new materials that improve their surface polishing due to their reduced size filler particles. This fact provides a combination of good mechanical and polishing properties [21]. In the study, an optical technique was used for assessing surface roughness of the resin composites as it had several advantages over the stylus instruments. A noncontact acquisition excludes surface damages that could be caused by the mechanical sensor and that could consequently create a bias in the results obtained. Moreover, it can measure an area from the surface rather than a single line in profilometry [22]. Furthermore, the procedure is an in-process approach which is amenable for automation. Thus, the roughness values obtained are more accurate, especially when viewing an exceptionally smooth surface like that of new nanocomposites [23]. Two types of composite resin restorations were used in this study. Nanohybrid universal resin composites (Mosaic) Group (A1), which is a bis-GMA-based universal nanohybrid, contains filler particles composed of zirconia-silica glass-ceramic and 20 -nanometer silica. The filler load is $56 \%$ by volume for the enamel shades and (Harmonize) Group (A2) which is a nanohybrid universal resin composite composed of spherical silica and zirconia particles with Adaptive Response Technology (ART) - elements of the filler system which actually have two components. First, the zirconia and silica nanoparticles are in an arrangement that imparts special optical properties as claimed by the manufacturer. The second component of the ART filler system is a rheological modifier, which acts as a stabilizing network if left undisturbed and under this condition, the apparent viscosity of the material is higher, which prevents material creep, commonly known as "slump" [24]. In the clinical practice, 
transparent matrices such as a Mylar strip are preferred for forming resin composites and producing the smoothest resin composites surfaces with the highest gloss. However, resin composites polymerized with a clear matrix on the surface will leave a resin-rich surface layer that is easily abraded in the oral environment, exposing unpolished, rough, and inorganic filler material. Thus, polishing is required to prevent wear and discoloration on the resin-rich surface [25]. The Sof-Lex finishing discs and polishing systems were chosen as they are an example of multiple polishing systems that provide the highest polishing effect compared to other types of the polishing technique [26]. However, not all restorations can be polished with discs because of their flat, rather rigid form [27]. Polishing instruments that are universally applicable such as rubber points, brushes, and cups are preferable [28]. Hence, white polishing stones and Diacomp plus were used. Furthermore, it is clinically important to identify the less time-consuming and material-consuming finishing technique which allows the clinician to obtain the smoothest surface [16]. In this study, Mosaic resin composite samples recorded statistically significant lower surface roughness $(\mathrm{Ra})$ value than the Harmonize samples among all the finishing and polishing systems used in this study. This could be due to the surface characteristics of the resin composite [29]. Resin matrix and filler particles present different hardness values. During finishing-polishing procedures, if the fillers are significantly harder than the resin matrix, the matrix will be abraded away first, and the filler particles will be left at the surface, increasing the aggregate surface roughness [30]. Several studies have observed a correlation between filler size and surface roughness and that composites incorporating large fillers (10$50 \mu \mathrm{m})$ tend to be rougher than composites incorporating smaller fillers $(0.04-1 \mu \mathrm{m})$ [31]. Furthermore, it could be related to the grit size of the abrasive discs, where a larger grit resulted in a rougher surface [32]. This result corresponds to our expectations based on the filler sizes in each resin composite and to the difference in composition in these two composites (KERR and Mosaic) [24], [33]. This was in agreement with Abdurazaq and Al-Khafaji Abdulrazak [34] in a similar study on different types of resin composites which concluded that all composites exhibited surface roughness, wherein nanohybrid exhibited consistent results in surface roughness values. This was in accordance with the results exhibited in our study. Giacomelli et al. [35], in a similar study on different polishing systems and resin composites, concluded that all composites and polishing systems generally exhibit surface roughness. This disagreed with Yazici et al. [36], who compared Grandio which is a nanohybrid composite with Aelite with different types of resin composites and it had the highest surface roughness after finishing and polishing because this composite contains $1 \mu$ glass particles that stick out from the surface and increase surface roughness. An important factor is the intrinsic roughness of a composite material, which is determined by the size, shape, and quantity of the filler particles. During polishing, these particles can be worn away, rather than plucking out the large second particle from the resin itself. Eventually, the surfaces have smaller defects and better polish retention. The roughest surface among resin composites tested Barium glass filler [34]. Under the condition of this study, the control group of all resin composites cured against the celluloid matrix exhibited the lowest mean surface roughness $(\mathrm{Ra})$ values. These results agreed with other studies Al Tabakh et al. [37], Borges et al. [38], and Helena et al. [39] which may be attributed to the absolute smooth surface of the celluloid strips. Furthermore, untreated resin composite surfaces with any finishing and polishing systems result in filler particles that were not be abraded away from the resin matrix, which finally leading to the creation of the smoothest surface of the tested resin composites. Furthermore, in agreement with Magdy et al., [40] who concluded that Mylar strip produced the smoothest surface in all restorative resin composite groups tested and they stated that the efficiency of abrasive systems is usually related to the flexibility of the backing material, in which the abrasive is embedded; hardness of the abrasive, geometry of the instrument, and how the instruments are used. This was in disagreement with Gönülol N and Yilmaz [41], who reported that there was no significant difference in resin composites samples finished with Sof-Lex system and that cured against a celluloid strip. This may be attributed to the use of water coolant during the finishing process with Sof-Lex. They suggested that besides drawing off heat, the water leaches the eroded particles, which must be removed immediately from the surface of the restoration. For a resin composites restorative material finishing system to be effective, the abrasive particles must be relatively harder than the filler materials. Otherwise, the polishing system will remove only the soft resin matrix and leave the filler particles protruding from the surface [42]. In this study, among the tested finishing and polishing systems, samples finished with Sof-Lex system recorded the low mean surface roughness $(\mathrm{Ra})$ value. This was in agreement with other studies [41] and could be explained by the sequential use of different aluminum oxide grits ranging from course to superfine in Sof-Lex finishing system. Another explanation reported by Neme et al. [43] who explained this result as the abrasive in the Sof-Lex ${ }^{\mathrm{TM}}$ disc was finer than that of other finishing and polishing systems used. The reason for the aluminum oxide (Sof-Lex) discs giving good surface smoothness could be due to the nondisplacement of the composite filler particles by SofLex, as stated by Herrgott et al. [44]. The aluminum oxide discs (Sof-Lex) performed better because the fillers in the composite are so small that their stiffness is reduced and so their malleability promotes a homogeneous abrasion of the fillers and the resin matrix [45]. A study by Mitra et al. [46] also supported 
the concept of homogeneous abrasion. The limited use of aluminum oxide discs is related to their shapes, which reduce their efficiency, particularly in the posterior areas of the oral cavity as stated by Helena et al. [39]. This could be related to the ability of the Sof-Lex discs to abrade the filler particles and the resin matrix at equal rate. Furthermore, the hardness of the abrasive particles of Sof-Lex that exceeds most filler particles of different resin composites resulted in a smooth surface, as stated by El Din [47]. Sibel et al. [48] in their study supported the Sof-Lex to achieve the lowest roughness value, among the other finishing and polishing systems used in their study, as the hardness of the aluminum oxide impregnated discs of Sof-Lex is higher than most filler particles in resin composites. However, the use of Sof-Lex system is limited to the accessible convex surfaces, so other finishing systems could be used to produce complex occlusal anatomy or concave surfaces, as stated by Jung [49]. This result was in disagreement with Erdemir et al. [28], who mentioned that there was no significant difference found between Sof-Lex system and Enhance/PoGo system. This disagreement may be due to the differences in our study and his study regimen which used 1200-grit silicon carbide abrasive paper ( $\mathrm{SiC}$ ) on a rotary polisher, and also the use of different resin composites materials (FiltekTM Supreme XT and Grandio) than those used in this current study. In the current study, the highest mean surface roughness (Ra) value for all tested resin composites was obtained when finished with a white polishing stone. This could be due to the lower hardness of these polishing particles as compared to a diamond might have increased the final roughness of the nanohybrid composite tested in the current study due to the possibly poorer abrasivity of the large glass particles of the nanohybrid [50]. Previous studies have shown that brushes and rubber polishers may partially remove the resin matrix or even extract filler particles, resulting in a rougher surface [51]. The use of the rubber polisher with decreasing abrasiveness both for the finishing phase and the polishing one is a technique which is not able to give a surface as smoother as the one obtainable with the other techniques described in this study also, the use of rubber polisher alone does not provide a sufficiently smooth surface with respect to the baseline. These results can be explained by the excessive rigidity of the rubber polisher and their gradual wear [52].

\section{Conclusion}

Achieving long-lasting esthetics in resin composites restorations needs special attention for obtaining optimal resin polymerization and a perfect surface finish using the appropriate finishing and polishing system.

\section{References}

1. Ramos R, Chinelatti M, Chimello D, Dibb R. Assessing microleakage in resin composite restorations rebonded with a surface sealant and three low-viscosity resin systems. Quintessence Int. 2002;33(6):450-6.

2. Ferracane J. Developing a more complete understanding of stresses produced in dental composites during polymerization. Dent Mater. 2005;21(1):36-42. https://doi.org/10.1016/j. dental.2004.10.004

PMid:15681000

3. Anusavice K. Philips' Science of Dental Materials. $11^{\text {th }}$ ed. Philadelphia, PA, United States: Saunders; 2003.

4. Bowen RL. Dental filling material compressing vinyl silane treated fused silica and a binder consisting of the reaction product of bisphenol and glycidyl methacrylate. US Pat. 1962;3(66):112.

5. Leinfelder K. Posterior composite resins: The materials and their clinical performance. J Am Dent Assoc. 1995;126(5):663-4, 667-8, 671-2. https://doi.org/10.14219/jada.archive.1995.0247 PMid:7759692

6. Senawongse P, Pongprueksa P. Surface roughness of nanofill and nanohybrid resin composites after polishing and brushing. J Esthet Restor Dent. 2007;19(5):265-75. https://doi. org/10.1111/j.1708-8240.2007.00116.x

\section{PMid:17877626}

7. Dresch W, Volpato S, Gomes JC, Ribeiro NR, Reis A Loguercio AD. Clinical evaluation of a nanofilled composite in posterior teeth: 12-month results. Oper Dent. 2006;31(4):40917. https://doi.org/10.2341/05-103

PMid:16924980

8. Korkmaz Y, Ozel E, Attar N, Aksoy G. The influence of one-step polishing systems on the surface roughness and microhardness of nanocomposites. Oper Dent. 2008;33(1):44-50. https://doi. org/10.2341/07-28

PMid:18335732

9. Morgan M. Finishing and polishing procedures of direct posterior resin restorations Pract Proced Aesthet Dent. 2004;16(3):211-7. PMid:15199696

10. Halim N, Maria T, Haline D, Fernanda P. Surface roughness of composite resins after finishing and polishing. Braz Dent J. 2003;14(1):37-41. https://doi.org/10.1590/ s0103-64402003000100007

PMid:12656463

11. Farahat F, Daneshkazemi A, Hajiahmadi Z. The effect of bulk depth and irradiation time on the surface hardness and degree of cure of bulk-fill composites. J Dent Biomater. 2016;3(3):284-91. PMid:28959755

12. Delgado A, Ritter A, Donovan T, Ziemiecki T, Heymann H. Effect of finishing techniques on the marginal integrity of resin-based composite and resin-modified glass ionomer restoration. J Esthet Restor Dent. 2015;27(4):184-93. https://doi.org/10.1111/ jerd. 12140 PMid:26177046

13. Suzuki T, Kyoizumi H, Finger WJ, Kanehira M, Endo T, Utterodt A, et al. Resistance of nanofill and nanohybrid resin composites to toothbrush abrasion with calcium carbonate slurry. Dent Mater J. 2009;28(6):708-16. https://doi.org/10.4012/dmj.28.708 PMid:20019422

14. Lemos C, Mauro S, Dos Santos P, Briso A, Fagundes T. Influence of mechanical and chemical degradation in the surface roughness, gloss, and color of microhybrid composites. J Contemp Dent Pract. 2017;18(4):283-8. https://doi.org/10.5005/ 
jp-journals-10024-2032

PMid:28349905

15. Kumari C, Bhat $\mathrm{K}$, Bansal R. Evaluation of surface roughness of different restorative composites after polishing using atomic force microscopy. J Conserv Dent. 2016;19(1):56-62. https:// doi.org/10.4103/0972-0707.173200

PMid:26957795

16. Marco C, Lodovico V, Riccardo B, Ricaldone F, Marco C, Claudio P. Effect of different finishing/polishing procedures on surface roughness of ormocer-based and different resin composites. Dent Res J (Isfahan). 2018;15(6):404-10. https:// doi.org/10.4103/1735-3327.245232

PMid:30534168

17. Kemaloglu H, Karacolak G, Turkun LS. Can reduced-step polishers be as effective as multiple-step polishers in enhancing surface smoothness. J Esthet Restor Dent. 2017;29(1):31-40. https://doi.org/10.1111/jerd.12233

PMid:27393008

18. Barghi N, Lind SD. A guide to polishing direct composite resin restorations. Compend Contin Educ Dent. 2000;21(2):138-42, 144. PMid:11199694

19. Shayan M, Jung Y, Huang PS, Moradi M, Plakseychuk A, Lee J, et al. Improved osteoblast response to UV-irradiated PMMA/ TiO2 nanocomposites with controllable wettability. J Mater Sci Mater Med. 2014;25(12):2721-30. https://doi.org/10.1007/ s10856-014-5284-3

PMid:25074833

20. Jung M, Sehr K, Klimek J. Surface texture of four nanofilled and one hybrid composite after finishing. Oper Dent. 2007;32(1):45-52. https://doi.org/10.2341/06-9 PMid: 17288328

21. Scheibe K, Almeida K, Medeiros I, Costa J, Alves C. Effect of different polishing systems on the surface roughness of microhybrid composites. J Appl Oral Sci. 2009;17(1):21-6. https://doi.org/10.1590/s1678-77572009000100005 PMid:19148401

22. Kumar R, Kulashekar B, Dhanasekar B, Raamamoorthy B. Application of digital image magnification for the surface roughness evaluation using machine vision. Int $\mathrm{J}$ Mach Tools Manuf. 2005;45(2):228-34. https://doi.org/10.1016/j. ijmachtools.2004.07.001

23. Joniot S, Salomon J, Dejou J, Gregoire G. The use of two surface analyzers to evaluate the surface roughness of four esthetic restorative materials after polishing. Oper Dent. 2006;31(1):3946. https://doi.org/10.2341/04-166

PMid:16536192

24. Kerr Restorative-Harmonize Universal Composite; 2020. Available from: http://www.kerrdental.com. [Last accessed on 2020 Jan 20].

25. Eden E, Cogulu D, Attin T. The effect of finishing and polishing systems on surface roughness, microhardness and microleakage of a nanohybrid composite. J Int Dent Med Res. 2012;5(3):155-60.

26. Erdemir U, Yildiz E, Eren M, Ozsoy A, Topcu F. Effects of polishing systems on the surface roughness of tooth-colored materials. J Dent Sci. 2013;8(2):160-9. https://doi.org/10.1016/j. jds.2012.05.007

27. Roeder L, Tate W, Powers J. Effect of finishing and polishing procedures on the surface roughness of packable composites. Oper Dent. 2000;25(6):534-43.

PMid:11203867

28. Marigo L, Rizzi M, La Torre G, Rumi G. 3-D surface profile analysis: Different finishing methods for resin composites. Oper Dent. 2001;26(6):562-8.

PMid:11699179
29. Endo T, Finger W, Kanehira M, Utterodt A, Komatsu M. Surface texture and roughness of polished nanofill and nanohybrid resin composites. Dent Mater J. 2010;29(2):213-23. https://doi. org/10.4012/dmj.2009-019

PMid:20379033

30. Uçtaşli M, Arisu H, Omürlü H, Eligüzeloğlu E, Ozcan S, Ergun G. The effect of different finishing and polishing systems on the surface roughness of different composite restorative materials. J Contemp Dent Pract. 2007;8(2):89-96. https://doi.org/10.5005/ jcdp-8-2-89

PMid: 17277831

31. Ferracane JL. Resin composite state of the art. Dent Mater 2011;27(1):29-38. https://doi.org/10.1016/j.dental.2010.10.020 PMid:21093034

32. Komalsingsakul A, Klaophimai A, Srisatjaluk RL, Senawongse $P$. Effect of the surface roughness of composite resins on the water contact angle and biofilm formation. M Dent J. 2019;39(2):75-84 .

33. Restorative-Mosaic Composite Resin; 2020. Available from: http:// www.ultradent.com. [Last accessed on 2020 Jan 20].

34. Abdurazaq $\mathrm{M}, \mathrm{Al}-\mathrm{Khafaji} \mathrm{A}$. The effect of different finishing and polishing systems on surface roughness of new low polymerized composite materials-an in vitro study. J Baghdad Coll Dent. 2013;25(2):24-30. https://doi.org/10.12816/0014927

35. Giacomelli L, Derchi G, Frustaci A, Orlando B, Covani U, Barone A, et al. Surface roughness of commercial composites after different polishing protocols: An analysis with atomic force microscopy. Open Dent J. 2010;4:191-4. https://doi. org/10.2174/1874210601004010191

PMid:21228920

36. Yazici A, Tuncer D, Antonson S, Onen A, Kilinic E. Effect of delayed finishing and polishing on surface roughness, hardness, and gloss of tooth colored restorative materials. Eur J Dent. 2010;4(1):50-6. https://doi.org/10.1055/s-0039-1697808 PMid:20046480

37. El Tabbakh A, Fayed T, Nouman K. In vitro study of the effect of some finishing and polishing techniques on surface roughness of various resin composites. Al Azhar J Dent Sci. 2005;6:60-9.

38. Borges A, Pagani C, Rodrigues J. Surface roughness of packable composite resins polished with various systems. J Esthet Restor Dent. 2004;16(1):42-8. https://doi. org/10.1111/j.1708-8240.2004.tb00451.x PMid:15259542

39. Helena S, Luiza R, Fidela M, Benoni O. Effect of different finishing and polishing techniques on the surface roughness of microfilled, hybrid and packable composite resins. Braz Dent J. 2005;16(1):39-44. https://doi.org/10.1590/ s0103-64402005000100007

PMid:16113932

40. Nashaat M, Mohamed Z, Hamod H, Mubarak D, Abdullah S Evaluation of surface roughness of different direct resin-based composites. J Int Soc Prev Community Dent. 2017;7(3):104-9. PMid:28584779

41. Gönülol N, YilmazF. The effects of finishing and polishing techniques on surface roughness and color stability of nanocomposites. J Dent. 2012;40(2):e64-70. https://doi.org/10.1016/j.jdent.2012.07.005 PMid:22819955

42. Fawad N. Effect of different polishing procedures on color stability of nanocomposites in different mouth rinses. Restor Dent. 2013;4(2):172-9.

43. Neme A, Frazier K, Roeder L, Debner T. Effect of prophylactic polishing protocols on the surface roughness of esthetic restorative materials. Oper Dent. 2003;27(1):50-8.

PMid:11817469

44. Herrgott A, Ziemiecki T, Dennison J. An evaluation of different composite resin systems finished with various abrasives. J Am 
Dent Assoc. 1989;119(6):729-32. https://doi.org/10.14219/jada archive.1989.0266

PMid:2592699

45. Yap A, Yap S, Teo C, Ng J. Finishing/polishing of resin composite and compomer restoratives: Effectiveness of one-step systems. Oper Dent. 2004;29(3):275-9.

PMid: 15195727

46. Mitra S, Wu D, Holmes B. An application of nanotechnology in advanced dental materials. J Am Dent Assoc. 2003;134(10):1382-90. https://doi.org/10.14219/jada. archive.2003.0054

PMid:14620019

47. Eldin SS, El-Yassaky M, El-Sharkawy D. Color stability of resin composites of different filler size polished with two different polishing techniques. Al Azhar J Dent Sci. 2011;5:40-9.

48. Sibel A, Yazici A, Kilinc E, Antonson D, Hardigan P. Comparison of different finishing/polishing systems on surface roughness and gloss of resin composites. J Dent. 2011;39(1):e9-17. https:// doi.org/10.1016/j.jdent.2011.01.006

PMid:21256180

49. Jung M. Finishing and polishing of a hybrid composite and a heat-pressed glass ceramic. Oper Dent. 2002;27(2):175-83.

PMid:11931137

50. Schmidlin P, Sener B, Lutz F. Cleaning and polishing efficacy of abrasive-bristle brushes and a prophylaxis paste on resin composite material in vitro. Quintessence Int 2002;33(9):691-9

PMid:12666895

51. Venturini D, Cenci M, Demarco F, Camacho G, Powers J. Effect of polishing techniques and time on surface roughness, hardness and microleakage of resin composite restorations. Oper Dent. 2006;31(1):11-7. https://doi.org/10.2341/04-155

PMid: 16536188

52. Ryba T, Dunn W, Murchison D. Surface roughness of various packable composites. Oper Dent. 2002;27(3):243-7.

PMid:12022454 